\title{
ФИЛЬТРЫ НИЖНИХ ЧАСТОТ НА ОСНОВЕ КРИСТАЛЛОПОДОБНЫХ НЕОДНОРОДНОСТЕЙ
}

\author{
Е. А. НЕЛИН, Я. Л. ЗИНГЕР, В. И. ПОПСУЙ \\ Национальный технический университет Украиньл \\ «Киевский политехнический институт им. Игоря Сикорского», \\ Украина, Киев, 03056, пр-т Победы 37
}

\begin{abstract}
Аннотация. Предложены микрополосковые фильтры нижних частот (ФНЧ) на основе трехмерных электромагнитнокристаллических неоднородностей (ЭКН). Выполнено сравнение расчетных амплитудно-частотных характеристик (АЧХ) квазисосредоточенных реактивных элементов на основе традиционных структур и ЭКН. АЧХ квазисосредоточенных реактивных элементов на основе ЭКН значительно ближе к АЧХ сосредоточенных элементов. Частота первого минимума АЧХ ФНЧ на основе ЭКН в три раза превышает аналогичную частоту на основе традиционных структур. Предложены совмещенные ЭКН, содержащие индуктивный и емкостный элементы. Представлены структуры ФНЧ на основе одиночных и совмещенных ЭКН. Приведены расчетные и экспериментальные параметры и АЧХ фильтров, иллюстрирующие значительное уменьшение размеров и улучшение характеристик в полосе подавления по сравнению с фильтром традиционной структуры. Характеристики рассчитаны трехмерным электромагнитным моделированием в программном пакете CST Microwave Studio.
\end{abstract}

Ключевые слова: микрополосковая структура; электромагнитнокристаллическая неоднородность; фильтр нижних частот; ФНЧ

\section{ВВЕДЕНИЕ}

Микрополосковые устройства широко применяют в различных радиоэлектронных системах. Современное развитие микрополосковой техники в значительной степени связано с использованием искусственных материалов - метаматериалов, а также искусственных структур с особыми характеристиками $[1,2]$. К таким структурам относят кристаллоподобные структуры с зонными свойствами, аналогичными кристаллам. Микрополосковые кристаллоподобные структуры - электромагнитные кристаллы (ЭК), а также отдельные ЭК-неоднородности (ЭКН) в виде двумерных неоднородностей в микрополосковом проводнике или в металлизированной поверхности [3-5] ис- пользуют в конструкциях фильтров [6], антенн [7], делителей мощности [8].

Традиционные ЭКН двумерные. В $[9,10]$ предложены трехмерные ЭКН, важное достоинство которых состоит в существенном расширении диапазона эквивалентного волнового импеданса по сравнению с традиционными микрополосковыми структурами и двумерными ЭКН. Одно из следствий такого расширения - возможность реализации квазисосредоточенных реактивных элементов с увеличением в 1,5-4 раза значений реактивностей по сравнению с традиционными структурами таких же размеров [11].

Квазисосредоточенные реактивные элементы реализуются короткими по сравнению с длиной волны отрезками линии передачи 


\section{БИБЛИОГРАФИЧЕСКИЙ СПИСОК}

1. Hong, J.-S. Microstrip filters for RF/microwave applications. N. Y.: Wiley, 2011. 656 p.

2. Martin, F. Artificial transmission lines for $R F$ and microwave applications. New Jerse: Wiley, 2015. 520 p.

3. Xiao, J.-K. Defected microstrip structure. Encyclopedia of Electrical and Electronics Engineering. N. Y.: Wiley, 2013. P. 1-8.

4. Bhuiyan, M. S.; Karmakar, N. C. Defected ground structures for microwave applications. Encyclopedia of Electrical and Electronics Engineering. N. Y.: Wiley, 2014. P. 1-31.

5. Khandelwal, M. K.; Kanaujia, B. K.; Kumar, S. "Defected ground structure: fundamentals, analysis, and applications in modern wireless trends," Int. J. Antennas Propag., Vol. 2017, article ID 2018527, 22 p., 2017. DOI: 10.1155/2017/2018527.

6. Chen, L.; Li, X. Y.; Wei, F. "A compact quad-band bandpass filter based on defected microstrip structure," Frequenz, Vol. 71, No. 7-8, P. 311-316, 2017. DOI: 10.1515/freq-2016-0238.

7. Abdulhamid, M.; Rahim, M. K. A.; Musa, U. "Electromagnetic bandgap structure for antenna design," IOSR J. Electronics Commun. Eng., Vol. 10, No. 6, P. 25-27, 2015. URI: http://www.iosrjournals.org/iosr-jece/ papers/Vol.\%2010\%20Issue $\% 206 /$ Version-1/E01061252 7.pdf.

8. Mhatre, P.; Varavdekar, J. M. "A review on EBG based power dividers," IOSR J. Electronics Commun. Eng., Vol. 4, No. 3, P. 32-35, 2012. DOI: 10.9790/28340433235 .

9. Назарько, А. И.; Нелин, Е. А.; Попсуй, В. И.; Тимофеева, Ю.Ф. "Высокоизбирательный электромагнитный кристалл,” ЖТФ, Т. 80, № 4, С. 138-139, 2010. URI: http://journals.ioffe.ru/jtf/2010/04/page-138.html. ru.

10. Нелин, Е.А.; Назарько, А.И. "Высокоэффективные электромагнитнокристаллические неоднородности," ЖТФ, Т. 83, № 4, С. 146-148, 2013. URI: http://journals.ioffe.ru/jtf/2013/04/page-146.html.ru. 
11. Биденко, П. С.; Нелин, Е. А.; Назарько, А. И.; Адаменко, Ю. Ф. “Квазисосредоточенные реактивные элементы на основе кристаллоподобных неоднородностей," Известия вузов. Радиоэлектроника, Т. 58, № 11, C. 49-56. DOI: 10.20535/S0021347015110059.

12. Gard, R.; Bahl, I.; Bozzi, M. Micristrip lines and slotlines, 3rd ed. Boston, London: Artech House, 2013. $590 \mathrm{p}$.

Поступила в редакцию 18.05.2016
13. Нелин, Е. А. "Моделирование и повышение избирательности кристаллоподобных структур," ЖТФ, T. 74, № 11, C. 70-74, 2004. URI: http://journals. ioffe.ru/articles/8413.

14. Нелин, Е.А. "Краевая аподизация кристаллоподобных структур," ЖТФ, Т. 75, № 11, С. 120-121, 2005. URI: http://journals.ioffe.ru/articles/8718. 